\title{
Perceptual constancy in judgm ents of egocentric distance: prevailing binocular information
}

\author{
Constân cia per ceptiva em julgam en tos de distância egocên trica: \\ prevalência da inform ação binocular
}

\author{
Elton H. Matsushima ${ }^{1}$ \\ Igor O.Douchkin² \\ Nilton P. Ribeiro Filho ${ }^{3}$ \\ J osé A par ecido Da Silva ${ }^{4}$
}

\begin{tabular}{l} 
A BST R A CT \\
\hline Binocular cues were considered the prevailing information on specifying \\
depth since the beginning of vision research. In the present study, two \\
perceptual responses, the classical verbal report and a more recent method, \\
open-loop walking, were used to assess the role of binocular information \\
for egocentric distance perception. In two cue conditions environments, \\
full- and reduced-cue, observers judged and walked egocentric distances \\
of stimuli presented at eye-level, under binocular or monocular viewing. \\
Results indicated perceptual constancy for open-loop walking and binocular \\
responses, as well as poor performances under strong degradation on \\
visual information (reduced-cue under monocular viewing), thus presenting \\
evidence to support the fundamental role of binocular information on \\
perception of egocentric distances. Besides that, visually directed actions \\
could be adequate measures of perceived distance, with a better reliability \\
than verbal report, since they were quite free of intrusion of inferential \\
processes and perceptual tendencies. In addition, reduced head move- \\
ments, side-to-side as well as back and forth deflexion movements, could \\
have contributed to a near perfect coupling between binocular disparity \\
information and open-loop walking responses.
\end{tabular}

Keywords: Visual perception; Space perception; Motor skills; Walking
${ }^{1}$ Graduate Student.Universidade de São Paulo at Ribeirão Preto. Faculdade de Filosofia, Ciências e Letras de Ribeirão Preto. Laboratório de Psicofísica e Percepção; ${ }^{2}$ Laboratory Technician. Universidade de São Paulo at Ribeirão Preto. Faculdade de Filosofia, Ciências e Letras de Ribeirão Preto. Laboratório de Psicofísica e Percepção; ${ }^{3}$ PostDoctoral Visitant. Universidade de São Paulo at Ribeirão Preto. Faculdade de Filosofia, Ciências e Letras de Ribeirão Preto. Laboratório de Psicofísica e Percepção; ${ }^{4}$ Full Professor. Universidade de São Paulo at Ribeirão Preto. Faculdade de Filosofia, Ciências e Letras de Ribeirão Preto.

Correspondence concerning this article should be addressed to Elton H. Matsushima - Av. Bandeirantes, 3.900, CEP 14040-901, Ribeirão Preto, SP, Brasil (email: tolitoli@uol.com.br).

\section{INTRODUCTION}

Since the beginning of scientifical study of visual perception, binocular information was considered the prevailing information on specifying $\operatorname{depth}^{(1)}$. Following the invention of stereoscope by Wheatstone that created a whole new area of study in visual perception, the development of random-dot stereograms ${ }^{(2)}$, the discoveries on neural wiring of binocular disparity encoding ${ }^{(3,4)}$, and the arising of computational theory in visual perception investigation, several findings and models on binocular depth perception increased knowledge until present status ${ }^{(1,5-11)}$. The nature of binocular information may be a trade off between stereopsis and binocular suppression in order to providing stability and singleness of our visual world ${ }^{(8)}$.

Foley ${ }^{(5-7)}$ in a series of studies developed a model to account for binocular distance perception, that implies egocentric distance encoding, which shows a perceived pattern of overshooting of near distances and undershooting of far distances. His model proposed that all of the error found on binocular distance perception is due to misperception of egocentric distance signal and to differences in effective magnification in the eyes ${ }^{(6)}$. 
Marotta and his colleagues ${ }^{(9,10)}$ found that pictorial cues are useful for calibration of visuomotor tasks in the absence of binocular cues. In their experiments, observers reached by prehension or grip movements a visually available target, so specifying egocentric distances was vital for accurate accomplishment of those tasks. Binocular disparity was a reference cue for accurate performance, thus indicating its fundamental role in specifying egocentric distances. Another evidence for binocular cues essential role in egocentric distance perception is found on Beusmans' work ${ }^{(11)}$. He claims that cues from optical movement, as binocular disparity and binocular parallax, associated with optical flow cues, could calibrate pictorial cues, thus becoming useful cues for specifying egocentric distance.

Ribeiro-Filho, Matsushima, Gomes, Oliveira, and Da Sil$\mathrm{va}^{(12)}$ studied egocentric distance perception in visual alleys, presenting stimuli in proximal space (up to $2.5 \mathrm{~m}$ ). Their fullcue visual alley, was well lit and textured, whereas their dark alley had no illumination and were all black painted. In a verbal report paradigm, perceived egocentric distance was assessed from observation points with different slopes of regard, in the same level of stimuli and with a $48.8 \mathrm{~cm}$ elevation. Slopes of regard is the angle between a visual target and a line in eye height parallel to ground, called visually perceived eye level or VPEL ${ }^{(13)}$. Results showed that slope of regard is very dependent on binocular information, at least in the proximal space, for verbal report judgments. Again, a pictorial cue was calibrated by binocular information in order to become useful for egocentric distance perception. One may argue that slope of regard itself could not provide information for accurate perceived egocentric distance, but when associated, probably following an additive summation ${ }^{(14,15)}$, with binocular information, namely binocular disparity and fusional vergence, slope of regard achieves accuracy for specifying egocentric distance.

\section{PER CEIVED DIST ANCE MEA SUREMENT BY DIFFERENT} TYPESOFINDICATORS

Spatial perception researchers had employed preferentially verbal report of perceived spatial dimensions, even though this kind of response is very amenable to intrusion of inferential processes and perceptual tendencies ${ }^{(6,16-21)}$. Adaptation of a verbal report paradigm included some other researches that measured perceived distance by scalar psychophysical methods, magnitude estimates, fractionation methods, ratio estimates, and matching tasks ${ }^{(22,23)}$.

More recently, researches used indirect measurement of perceived distance through visuomotor tasks. Foley and Held $^{(24)}$ opened up this paradigm using an innovative method, a visually directed task, namely a task performed without continuous viewing of target, in the case of Foley and Held's experiments, blind pointing to a previously seen target.

By the 80 's, other researchers employed visually directed tasks to study visuomotor system itself and, consequently, visual perception. Thomson ${ }^{(25)}$, using visually directed walking tasks, investigated whether locomotion is directed toward an internal spatial representation, previously determined by visual perception. His results showed accurate locomotion toward distances up to 12 meters, thus allowing him to argue for mechanisms similar to motor programs or updating of an internal visual representation of the scene.

Conversely and more recently, several other researchers focused on building up an account for this internal varia$\mathrm{ble}^{(26-30)}$. The general finding was a adequate accuracy on open-loop walking (visually directed walking) toward egocentrically located targets at distances up to 15 meters $^{(26,27)}$, or up to 22 meters $^{(29)}$. Researchers usually explained this accuracy with the aforementioned accurate updating processes of internal representation of the scene previously seen.

Philbeck and Loomis ${ }^{(30)}$ found accuracy on perceived distances assessed by open-loop walking (visually directed walking) and verbal report, in full-cue and reduced-cue environments, thus arguing that an invariant affected both responses in both cue conditions. They considered angular declination (or slope of regard) as the prevailing information for accuracy, since other cues, as motion parallax and binocular cues, did not achieve statistical significance.

In the present study we will use these two perceptual responses, the classical verbal report of perceived distance and the open-loop walking, undergoing to assess the role of binocular information for egocentric distance perception. In the former method, memory of visual experience with spatial relations and measurement system, as well as cognitive processing and perceptual tendencies ${ }^{(6)}$, introduces an additional bias to perceived distance ${ }^{(31)}$.

\section{METHOD}

\section{Experimental Environment}

The experiments were accomplished in two different visual alleys: a full-cue and a reduced-cue alley. Full-cue alley dimensions were 1.9 m width $\times 8.4 \mathrm{~m}$ depth, with red, white and yellow squared texture covering floor and beige curtains on walls. Stimuli hung from the ceiling with adjustable height, suspended by nylon lines that were poorly visible to observers, and when reset to ceiling were not visible for observer in origin (Figure 1). Reduced-cue alley was a dark room, with black ceiling, floor and walls, with dimensions $1.75 \mathrm{~m}$ width and $7.4 \mathrm{~m}$ depth. Stimuli also hung from ceiling with adjustable height and were not visible to observers at origin when reset to ceiling. Stimuli could be at four egocentric distances (2.0, 3.0, 4.0, and $5.0 \mathrm{~m}$ ) from the origin (observer initial position).

\section{Participants}

80 undergraduate and technicians from University community $(40 \mathrm{M}, 40 \mathrm{~F})$, aged from 17 to 34 years old $(\mathrm{Md}=21)$, with minimum, corrected or not, visual acuity of 20/20, assessed by a Bausch \& Lomb Orthorater, naive to the aims of experiments, 


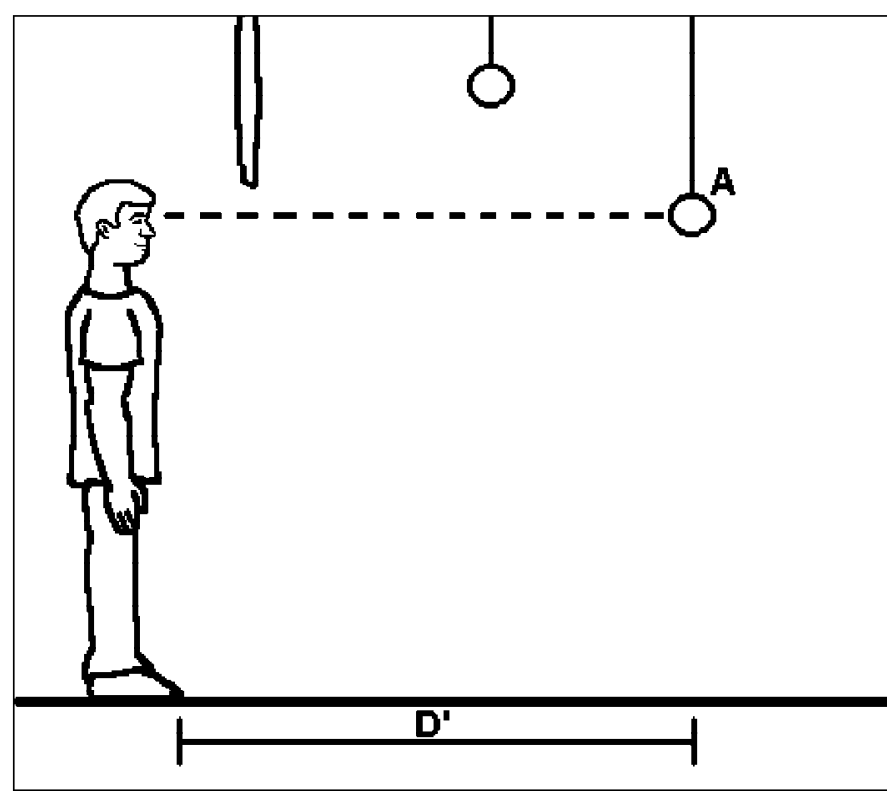

Figure 1 - Experimental environment from full-cue and from reduced-cue conditions. Stimulus at position A had its height adjusted to observers eye height. Instructions emphasize that distance D' must be the distance estimated, by verbal report as well as by open-loop walking

all paid, spontaneously participated of experiments and were equally divided (gender balanced) in 8 groups formed from between-groups variables.

\section{Stimuli and Materials}

In full-cue environments, stimuli were four white spheres with $7.5 \mathrm{~cm}$ diameter. In reduced-cue environments, stimuli were four translucent white spheres with $7.5 \mathrm{~cm}$ diameter with a tiny lamp inside. Lamps provided a constant luminance of $0.12 \mathrm{~cd} / \mathrm{m} 3$. Binocular and monocular blindfolds and ear-defenders were also used during the experiments. Visual acuity was assessed by a Bausch \& Lomb Orthorater, cat. 71-21-31, serial number $1353 \mathrm{LH}$.

\section{Design}

The experimental design was fully factorial with 4 betweensubjects factors, 2 cue conditions (full-cue and reduced-cue environments) x 2 egocentric distance indicators (verbal report and open-loop walking) x 2 viewing conditions (induced monocular and binocular), and 2 within-subjects factors, 3 trials $\mathrm{x} 4$ physical egocentric distances $(2,3,4$, and $5 \mathrm{~m})$, with dependent variable perceived egocentric distances.

\section{Procedures}

After visual acuity and ocular dominance tests, participants received objective instructions with a picture of figure 1. Participants from walking groups passed through a walking training to guarantee assurance on walking. Instructions emphasized that observers must consider the distance between their eyes and the object for the estimates or walkings. Additional measurement of observers' height were taken for height adjustment of stimuli. After all these pre-experiment procedures, participants were instructed to observe stimulus position, and to produce the adequate response, walking or verbal report. Walking responses consisted of blind walking toward stimulus position (that was already lifted for participant security), precise position was measured by ankle position. Verbal report consisted in verbal indication of how far was the object from observer's eyes, in meters, centimeters, or a combination of both. Participants received no feedback about accuracy or errors after any trial.

\section{RESULTS}

For distilling data in search for perceptual constancy phenomena, power-function fits were applied over perceived egocentric distance as a function of physical egocentric distance. Exponents greater than unity characterize perceptual overconstancy, perceived distance as an positively accelerated function of physical distance, in contrast, exponents lower than unity indicate perceptual underconstancy, perceived distance as negatively accelerated function of physical distance. Means and standard deviations of power-function parameters and of coefficients of determination $\left(r^{2}\right)$ were summarized in table 1 .

A quick inspection on data indicated that perceptual constancy broke down in reduced-cue environments comparing to

\begin{tabular}{|c|c|c|c|c|c|c|c|c|}
\hline \multirow{2}{*}{$\begin{array}{l}\text { Parameters of } \\
\text { Power-functions }\end{array}$} & \multicolumn{4}{|c|}{ Full-Cue Environments } & \multicolumn{4}{|c|}{ Reduced-Cue Environments } \\
\hline & Mono & Bino & Mono & Bino & Mono & Bino & $\frac{\text { Open-loop }}{\text { Mono }}$ & $\frac{\text { Walking }}{\text { Bino }}$ \\
\hline \multirow[t]{2}{*}{$r^{2}$} & .979 & .973 & .982 & .993 & .917 & .980 & .985 & .934 \\
\hline & $(.023)$ & $(.022)$ & $(.019)$ & $(.006)$ & $(.124)$ & $(.017)$ & $(.012)$ & $(.083)$ \\
\hline \multirow[t]{2}{*}{ Constant } & .841 & .899 & .769 & .746 & .353 & .789 & .668 & 1.077 \\
\hline & $(.435)$ & $(.380)$ & $(.301)$ & $(.182)$ & $(.202)$ & $(.289)$ & $(.256)$ & $(.302)$ \\
\hline
\end{tabular}


full-cue environments, specially when combined with monocular viewing, except for open-loop walking responses (Figure 2). Full-cue environments provided observers sufficient visual information, even under monocular viewing, yielding efficacy of texture gradient and perspective information, associated with whatever oculomotor cues that was present in environment, binocular disparity and fusional vergence when under binocular viewing, and accommodative vergence when only monocular information was available. Conversely, in reduced-cue environments, roughly accurate performance was achieved only when binocular information was available. In the absence of other monocular cues, accommodative vergen-

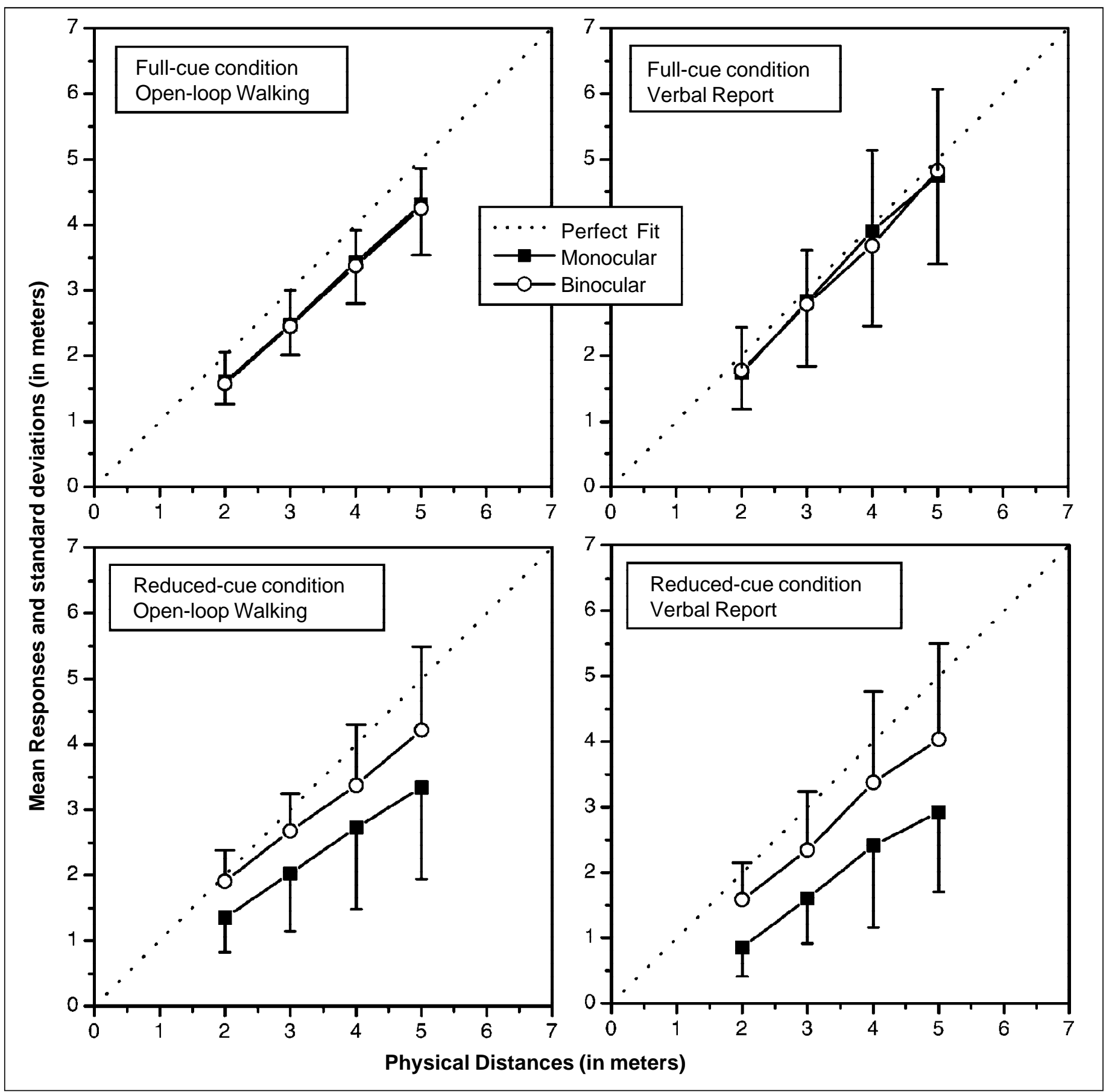

Figure 2. Mean responses and standard deviations as a function of physical distances, in meters. Upper Panels summarize data from Full-cue environments, and Lower Panels, from reduced-cue environments. Left Panels summarize data from Open-loop Walking groups, Right Panels, from Verbal Report groups. Solid squares represent responses made under monocular viewing, and open circles, under binocular viewing. Dotted line represents perfect fit between perceived and physical distances. Small caps represent standard deviations of responses made under monocular viewing, and large caps, under binocular viewing. Standard deviation bars are represented in a single direction for better visualization 
ce poorly specified egocentric distance, being very amenable to perceptual tendencies, as specific distance tendency ${ }^{(18,19)}$.

We applied an ANOVA over individual exponents, following a factorial design with 4 between-groups factors, 2 cue conditions (full-cue and reduced-cue environments) x 2 egocentric distance indicators (verbal report and open-loop walking) $x 2$ viewing conditions (induced monocular and binocular), with dependent variable exponents from power-function fits. Results showed reliable differences for main factors, indicators, $F(1,72)=9.759, p=.003$, and viewing conditions, $F(1,72)=8.549, p=.005$, and for interaction between cue conditions $\mathrm{x}$ indicators, $F(1,72)=7.620, p=.007$. Marginal differences appeared for interaction between cue conditions $\mathrm{x}$ viewing conditions, $F(1,72)=5.221, p=.025$.

In order to verify perceptual constancy that is indicated by the exponent equal to unity, we applied one sample t-tests with comparison value equal unity to exponents from each level of grouping variables and their interactions. Reliable equality will be considered only when no differences, even marginal, were found. Exponents from verbal report estimates were reliably greater than unity, $t(39)=3.608, p=.001$, although, for open-loop walking, equality to unity was found, $t(39) .355, p=.725$. Exponents from responses made under monocular viewing were significantly larger than unity, $t(39)=$ $3.769, p=.001$, in contrast to exponents from binocular viewing that was equal to unity, $t(39)=.445, p=.659$. Analyzing reliable interactions shown on ANOVA, exponents from full-cue environments in both indicators presented exponents greater than unity, $t(39)=2.352, p=.030$ (for verbal report) and $t(39)=$ $3.243, p=.004$ (for open-loop walking), but in reduced-cue environments, only verbal report produced exponents greater than unity, $t(39)=2.760, p=.012$. Exponents of responses made under monocular viewing in full- and reduced-cue environments were greater than unity, $t(39)=2.938, p=.008$ and $t(39)=2.618, p=.017$, respectively.

These analysis yield that binocular information was a predictor of perceptual constancy, as well as the visuomotor indicator of perceived egocentric distance, open-loop walking in reduced-cue environments. One could argue that binocular disparity and fusional vergence, at least in near space (up to $5 \mathrm{~m}$ ), provided observers with accurate egocentric distance information, even when environmental conditions was degraded (reduced-cue environment). One could also argue that open-loop walking, as a response that is quite free of cognitive and inferential process intrusion, produced perceptual constancy in reduced-cue environment, a typical situation in which cognitive factors, such as specific distance tenden$\mathrm{cy}^{(18,19)}$, usually occur with enough strength.

A secondary finding was main factor physical distances reliable effects that just tell us about observer's discriminability of egocentric distances. Other reliable effects, as cue and viewing conditions manipulations, just provided more evidence for an unambiguous finding in vision research: the richer the visual information, the better will be performance on perceptual tasks ${ }^{(32)}$.

\section{DISCUSSION}

Comparing our results to eye-level conditions on Philbeck and Loomis' Experiments ${ }^{(30)}$, one can readily point out great differences between results, even though, methods and procedures were roughly similar. In Loomis' commentary ${ }^{(13)}$, he stressed the more informative feature of reduced-cue conditions, as the availability of cues (as found in our full-cue environment) did not allow fruitful interpretations on cue effectiveness. So analysis concentrated on reduced-cue environments, considering full-cue environments data only as control groups. In reduced-cue environments, they found positive errors on proximal stimuli (up to $2.6 \mathrm{~m}$ ) that progressively developed to negative errors on distal stimuli (from 4.15 to $5.0 \mathrm{~m}$ ). On the other hand, our results confidently showed ac-curacy and constancy on perceived egocentric distance for both indicators under binocular viewing. These differences may be due and proportional to use of adapting panel $\left(310 \mathrm{~cd} / \mathrm{m}^{3}\right)$ to avoid observation of environment with the dim illumination provided by stimulus $\left(.51 \mathrm{~cd} / \mathrm{m}^{3}\right)$ and strings of light on the floor. After-effects of the adapting panel could have caused confusion or impaired adequate responses.

When graphical plots of perceived distances as a function of physical distances show a line parallel to abscissa, this indicates contradictory visual information, and when show a perfect fit, indicates consistent visual information ${ }^{(33)}$. Their graphical plots for reduced-cue conditions for both indicators showed the parallel pattern, as our results presented a linear almost perfectly adjusted pattern, at least for binocular conditions.

This statement could be better applied for open-loop walking responses that presented perceptual constancy. This constancy supports the claim for a useful source of information, whereas verbal report responses, that did not presented that constancy, were clearly affected by a non-perceptual source of information. Since the same dichotomy in perceptual constancy appeared in viewing conditions, to the extent that responses under binocular viewing presented perceptual constancy in contrast to responses under monocular viewing, one could argue for binocular disparity as the underlying source providing invariant information in control of responses. Hence, there must exist another source of information besides binocular disparity conveying the compelling perceptual constancy yielded in open-loop walking responses. One could suppose that some sort of interaction between visuomotor and vestibular systems may have occurred in both environmental conditions ${ }^{(34-36)}$. The absence of back and forth head deflexion induced by eye-level presentations restrained otolithic system function ${ }^{(34)}$, thus allowing a near perfect coupling between binocular disparity information and open-loop walking tasks. Otolithic function was restrained, but not inhibited for its effectiveness during straight ahead walking, in which head and body acceleration "pushes" otoliths towards stereociliae, thus producing firing rates in receptor ${ }^{(34)}$. 


\section{CONCLUSIONS}

The present results showed performances on egocentric perception, as assessed by two behavioral indicators (verbal report and open-loop walking), in a situation of a great degradation in the availability of visual cues including monocular viewing, presenting large compression of space, nearly the predicted distance of specific distance tendency $(2.0 \mathrm{~m})^{(16,17)}$. The addition of binocular information produced a noticeable increase in accuracy, presenting evidence to support the fundamental role of binocular information on perception of egocentric distances ${ }^{(6-7,31)}$.

Secondary to this finding, one could argue that visually directed actions could be adequate measures of perceived distance, since their reliability is indeed even better than verbal report, since they could be quite free of intrusion of inferential processes and perceptual tendencies.

A third conclusion is about the feasible interaction between visuomotor and vestibular systems. In our stimuli presentations, adjusted to observer's eye-level, vestibular information was greatly constrained by reduced (or even absent) head movements, side-to-side as well as back and forth deflexion movements ${ }^{(34)}$. This could have contributed to near perfect coupling between binocular disparity information and open-loop walking responses. Without strong signals from vestibular system, observers must have relied on previous visual information for accomplishment of walking tasks.

\section{RESUMO}

Os indícios binoculares foram considerados a informação prevalente na determinação da profundidade desde os primórdios da pesquisa em visão. No presente estudo, duas respostas perceptivas, o clássico relato verbal e um método mais recente, o caminhar em ciclo aberto, foram empregados para verificar o papel da informação binocular na percepção de distâncias egocêntricas. Em duas condições de indícios, plena e reduzida de indícios visuais, os observadores julgaram e caminharam distâncias egocêntricas de estímulos apresentados no nível do olho, sob visão binocular ou monocular. Os resultados indicaram constância perceptual para caminhar em ciclo aberto e respostas sob visão binocular, assim como baixa performance sob forte degradação da informação visual (condição reduzida de indícios sob visão monocular), nos fornecendo subsídios para sustentar o papel fundamental da informação binocular na percepção de distâncias egocêntricas. Além disso, as ações visualmente dirigidas podem ser medidas adequadas da distância percebida, com fidedignidade maior que o relato verbal, já que é relativamente incólume à intrusão de processos inferenciais e tendências perceptuais. Somando-se a isso, reduzidos movimentos da cabeça, tanto translacionais quanto deflexões para frente e para trás, podem ter contribuído para uma quase perfeita interação entre a disparidade binocular e as respostas de caminhar em ciclo aberto.
Descritores: Percepção visual; Percepção do espaço; Habilidades motoras; Caminhar

\section{ACK NOW LEDGMENTS}

We thank Tomaz Lazanha for his work on accomplishment of our experiments. Financial Support: PICD/UFRJ/CAPES 1999-2000 for third author, and CNPq 521852/93-5 for fourth author.

\section{REFERENCES}

1. Qian N(1) Qian N. Binocular disparity and the perception of depth. Neuron 1997; 18:359-68.

2. Julez B. Foundations of Cyclopean Perception. Chicago: University of Chicago Press; 1971.

3. Bishop PO, Pettigrew JD. Neural mechanisms of binocular vision. Vision Res 1986;26:1587-1600.

4. Poggio GF, Poggio T. The analysis of stereopsis. Annu Rev Neurosci 1984; 7:379-412.

5. Foley JM. Binocular disparity and perceived relative distance: an examination of two hypothesis. Vision Res 1967;7:655-70.

6. Foley JM. Binocular distance perception. Psychol Rev 1980;87(5):411-34.

7. Foley JM. Binocular distance perception: egocentric distance tasks. J Exp Psychol Hum Percept Perform 1985;11(2):133-49.

8. Arditi A. Binocular vision. In: Boff KR, Kaufman L \& Thomas JP, editors, Handbook of Perception and Human Performance. New York: Wiley-Interscience; 1986, p.23:1-40

9. Marotta JJ, Behrmann M, Goodale MA. The removal of binocular cues disrupts the calibration of grasping in patients with visual form agnosia. Exp Brain Res 1997;116:113-21.

10. Marotta JJ, Kruyer A, Goodale MA. The role of head movements in the control of manual prehension. Exp Brain Res 1998;120:134-8.

11. Beusmans JMH. Optical flow and the metric of the visual ground plane. Vision Res 1998;38(8):1153-70.

12. Ribeiro-Filho NP, Matsushima EH, Gomes BC, Oliveira LEMP, Da Silva JA. Evidences for the height in the visual field as an absolute distance cue in visual alley. In: Bonnett $\mathrm{C}$, Proceedings of the Annual Meeting of the International Society for Psychophysics. Strasburg: ISP; 2000.

13. Loomis JM. Looking down is looking up. Nature 2001;414:155-6.

14. Bruno N, Cutting JE. Minimodularity and the perception of layout. J Exp Psychol Gen 1988;117(2):161-70.

15. Cutting JE, Bruno N. Additivity, Subadditivity, and the use of visual information: a reply to Massaro (1988). J Exp Psychol Gen 1988;117(4):422-4.

16. Carlson VR. Instructions and perceptual constancy judgments. In: Epstein W, edit, Stability and Constancy in Visual Perception: Mechanism and Process. New York: John Wiley \& Sons; 1977, p.217-54.

17. Da Silva JA, Santos RA. The effects of instructions on scales for perceived egocentric distance in a large open field. Bull Psychon Soc 1984;22(3):189-92.

18. Gogel WC \& Tietz JD. Absolute motion parallax and the specific distance tendency. Percept Psychophys 1973;13(2):284-92.

19. Gogel WC. Cognitive factors in spatial responses. Psychologia 1974; 17:213-25.

20. Gogel WC. An indirect measure of perceived distance from oculomotor cues. Percept Psychophys 1977;21(1):3-11.

21. Gogel WC, Da Silva JA. A two-process theory of the response to size and distance. Percept Psychophys 1987;41:220-38.

22. Rozestraten RJA, Da Silva JA. Fracionamento de distâncias no laboratório e no campo aberto. Psicologia 1977;3(1):77-92.

23. Da Silva JA. Scales for perceived egocentric distance in a large open field: comparison of three psychophysical methods. Am J Psychol 1985;98(1):119-44.

24. Foley JM, Held R. Visually directed pointing as a function of target distance. Percept Psychophys 1972;12(3):263-8.

25. Thomson JA. Is continuous visual monitoring necessary in visually guided locomotion? J Exp Psychol Hum Percept Perform 1983;9(3):427-43.

26. Fukusima SS, Loomis JM, Da Silva JA. Visual perception of egocentric distance as assessed by triangulation. J Exp Psychol Hum Percept Perform 1997;23(1):86-100. 
27. Loomis JM, Da Silva JA, Fujita N, Fukusima SS. Visual space perception and visually directed action. J Exp Psychol Hum Percept Perform 1992;18(4): 906-21.

28. Steenhuis RE, Goodale MA. The effects of time and distance on accuracy of target-directed locomotion: does an accurate short-term memory for spatial location exist? J Mot Behav 1988;20(4):399-415.

29. Rieser JJ, Ashmead DH, Talor CR, Youngquist GA. Visual perception and the guidance of locomotion without vision to previously seen targets. Perception 1990; 19:675-89.

30. Philbeck JW, Loomis JA. Comparison of two indicators of perceived egocentric distance under full-cue and reduced-cue conditions. J Exp Psychol Hum Percept Perform 1997;23(1):72-85.

31. Da Silva, JA. Elevação angular como um indício de distância egocêntrica (Experimentos 1, 2 e 3). Technical Report No. 1 Ribeirão Preto, São Paulo:
Universidade de São Paulo, Faculdade de Filosofia, Ciências e Letras de Ribeirão Preto; 1999.

32. Künnapas T. Distance perception as a function of available visual cues. J Exp Psychol 1967;77(4):523-9.

33. Gogel WC, Tietz JD. A comparison of oculomotor and motion parallax cues of egocentric distance. Vision Res 1979;19:1161-70.

34. Lent R. Os detectores do ambiente - Receptores sensoriais e a transdução: primeiros estágios para a percepção. In: Lent $\mathrm{R}$, editor, Cem bilhões de neurônios: conceitos fundamentais de Neurociência. São Paulo: Atheneu; 2001: p.167-206.

35. Begelman DA. The role of retinal orientation in the egocentric organization of a visual stimulus. J Gen Psychol 1968;79(2):283-9.

36. Braine LG, Knox C. Children's orientation judgments: Retinally or environmentally determined? Percept Psychophys 1975;17(5):473-9. 